\title{
TWO-PHASE FLOW OF R245FA IN A 1 MM CORRUGATION DEPTH PLATE HEAT EXCHANGER - PART II: FLOW BOILING HEAT TRANSFER
}

\author{
F. Vakili-Farahani, ${ }^{1,2, *}$ R. L. Amalfi, ${ }^{1}$ \& J. R. Thome ${ }^{1}$ \\ ${ }^{1}$ Laboratory of Heat and Mass Transfer, LTCM, École Polytechnique Fédérale de Lausanne, Station \\ 9, CH-1015 Lausanne, Switzerland \\ ${ }^{2}$ Laboratory for Advanced Materials Processing, Swiss Federal Laboratories for Materials Science \\ and Technology (Empa), Feuerwerkerstrasse 39, CH-3602 Thun, Switzerland
}

*Address all correspondence to F. Vakili-Farahani, E-mail: farzad.vakilifarahani@empa.ch

\begin{abstract}
This article is the second in a two-part study on two-phase flow of R245fa in a new promising and more compact plate heat exchanger (PHE). Two-phase adiabatic frictional pressure drops were detailed in Part I, while the flow boiling heat transfer coefficients were obtained and the results presented here in Part II. Upward flow boiling heat transfer was investigated locally within the PHE prototype using an IR camera to measure the local PHE wall temperatures with high resolution. A new experimental approach for PHEs was introduced in order to reduce the data and obtain the local pixelby-pixel flow boiling heat transfer coefficients throughout the PHE. The influences of heat flux, mass flux, saturation temperature, vapor quality, and inlet condition on flow boiling heat transfer coefficients were obtainable. During the tests, the vapor qualities changed from 0 to 0.78 for mass fluxes from 7.5 to $40 \mathrm{~kg} \mathrm{~m}^{-2} \mathrm{~s}^{-1}$, heat fluxes from 250 to $3700 \mathrm{~W} \mathrm{~m}^{-2}$, and saturation temperatures from $19^{\circ} \mathrm{C}$ to $35^{\circ} \mathrm{C}$. In addition, comparative flow boiling experiments were carried out with a small subcooling and then repeated with liquid-vapor $\left(x_{i n} \approx 0.1-0.2\right)$ flow at the PHE inlet. Several of the most widely used prediction methods in the PHE literature were evaluated with respect to the current mean and quasi-local (obtained in six windows) experimental databases. The prediction methods mostly showed a better agreement with the mean flow boiling heat transfer coefficients rather than the local database.
\end{abstract}

KEY WORDS: two-phase flow, plate heat exchanger, flow boiling heat transfer, pressure drop, R245fa

\section{INTRODUCTION}

Plate heat exchangers (PHEs) have increasingly become the heat exchanger of choice in many small to medium size refrigeration systems. There is an ever important need to reduce their volumes, primarily to make the refrigeration systems more compact and secondly to reduce the refrigerant charge. In that light, the new thinner, smaller corrugation depth plate presented in Part I has the potential to fulfill this need, but its heat transfer coefficients need to be measured and correlated, which are the objectives here of Part II. Based on the literature, evaporation in confined corrugated channels of PHEs belongs mainly to convective dominated regime as the heat fluxes in applications are low as narrow temperature approaches between the evaporating fluid and the heating fluid (such as chilled water) are the norm. Below, a brief review of the relevant flow boiling literature in conventional size PHEs is given.

Danilova et al. (1981) conducted one of the first flow boiling experimental studies on PHEs, using the refrigerants R12, R22, R113, and ammonia. The evaporation heat transfer coefficients increased almost linearly with vapor quality and refrigerant mass flux. They proposed the following correlation to predict their flow boiling heat transfer results:

$$
\mathrm{Nu}_{t p}=\left\{\begin{array}{cc}
3 \operatorname{Re}_{v}^{0.3} \mathrm{Bd}^{0.33} & 0.025<\operatorname{Re}_{s}<0.25 \\
4.2 \operatorname{Re}_{v}^{0.3} \mathrm{Bd}^{0.33} \operatorname{Re}_{s}^{0.2} & 0.25<\operatorname{Re}_{s}<2.5
\end{array}\right.
$$




\section{NOMENCLATURE}

A area $\left[\mathrm{m}^{2}\right]$

b pressing depth [m]

$\mathrm{Bd} \quad$ Bond number [-]

Bo boiling number [-]

$\mathrm{c}_{p} \quad$ specific heat $\left[\mathrm{J} \mathrm{kg}^{-1} \mathrm{~K}^{-1}\right]$

Co convection number [-]

$\mathrm{d}$ diameter [m]

E enhancement factor [-]

$\mathrm{g} \quad$ acceleration due to the gravity $\left[\mathrm{m} \mathrm{s}^{-2}\right]$

$\mathrm{G}$ mass flux $\left[\mathrm{kg} \mathrm{m}^{-2} \mathrm{~s}^{-1}\right]$

$\mathrm{h}$ heat transfer coefficient [W $\mathrm{m}^{-2} \mathrm{~K}^{-1}$ ]

$\mathrm{i}_{l v} \quad$ latent heat of vaporization $\left[\mathrm{J} \mathrm{kg}^{-1}\right]$

I electrical current [A]

$\mathrm{J} \quad$ superficial velocity $\left[\mathrm{m} \mathrm{s}^{-1}\right]$

$\mathrm{k}$ thermal conductivity [ $\mathrm{W} \mathrm{m}^{-1} \mathrm{~K}^{-1}$ ]

L length [m]

$\dot{m} \quad$ mass flow rate $\left[\mathrm{kg} \mathrm{s}^{-1}\right]$

M molar mass $\left[\mathrm{kg} \mathrm{mol}^{-1}\right]$

MAE mean absolute error [-]

ME mean error [-]

$\mathrm{Nu} \quad$ Nusselt number [-]

$\mathrm{p}$ pressure $[\mathrm{Pa}]$

$\mathrm{P} \quad$ perimeter $[\mathrm{m}]$

Pr Prandtl number [-]

$\mathrm{q} \quad$ heat flux $\left[\mathrm{W} \mathrm{m}^{-2}\right]$

Q heat transfer rate [W]

Re Reynolds number [-]

$\mathrm{S} \quad$ suppression factor [-]

$\mathrm{T}$ temperature [K]

$\mathrm{V} \quad$ voltage $[\mathrm{V}]$

$\mathrm{W}$ width [m]

$\mathrm{x} \quad$ vapor quality [-]

X Lockhart and Martinelli parameter [-]

$\mathrm{z} \quad$ location along the flow [m]

\section{Greek Symbols}

$\beta \quad$ chevron angle $\left[{ }^{\circ}\right]$

$\Delta \quad$ difference [-]

$\Delta \mathrm{T}_{\text {sat }} \quad$ saturation to wall temperature difference $[\mathrm{K}]$

$\Lambda \quad$ wavelength of sinusoidal surface corrugation [m]

$\mu \quad$ dynamic viscosity [ $\mathrm{N} \mathrm{s} \mathrm{m}^{-2}$ ]

$\rho \quad$ density $\left[\mathrm{kg} \mathrm{m}^{-3}\right]$

$\sigma \quad$ surface tension $\left[\mathrm{N} \mathrm{m}^{-1}\right]$

$\phi \quad$ enlargement factor [-]

$\varphi^{2} \quad$ two-phase multiplier [-]

\section{Subscripts}

cam camera

$c b \quad$ convective boiling

ch channel

eff effective

$e q \quad$ equivalent

$\mathrm{fl} \quad$ fluid

$h \quad$ hydraulic

in inlet

$l \quad$ liquid

lo liquid-only

$m$ mean

$n b \quad$ nucleate boiling

out outlet

$p \quad$ port

pool pool boiling

$r \quad$ reduced

ref reference

refg refrigerant

sat saturation

$s p \quad$ single-phase

tp two-phase

$v \quad$ vapor

where $\mathrm{Bd}$ is the Bond number and $\mathrm{Bo}, \mathrm{Re}_{s}$, and $\mathrm{Re}_{v}$ are, respectively, the boiling and liquid-only and vapor-only Reynolds numbers but with $\mathrm{Bo}$ incorporated into the value of $\mathrm{Re}_{s}$ :

$$
\mathrm{Bd}=\frac{g \rho_{l} d_{h}^{2}}{\sigma}, \operatorname{Re}_{s}=\mathrm{Bo}_{\operatorname{Re}_{l o}}=\frac{q d_{h}}{i_{l v} \mu_{l}}, \quad \operatorname{Re}_{v}=\frac{G x d_{h}}{\mu_{v}}
$$

They also stated the imposed heat flux provided an enhancement in the heat transfer rate but the effect was less dominant compared to vapor quality and mass flux.

Donowski and Kandlikar (2000) analyzed the evaporation heat transfer coefficient data of Yan and Lin (1999). They concluded there was a large discrepancy between either the original single-phase or two-phase experimental data and the corresponding values predicted by the Yan and Lin (1999) correlation, with the correlation underpredicting 
all the database. Therefore, the Yan and Lin's PHE data were used to develop improved correlations for the singlephase heat transfer coefficient of water-to-water as well as two correlations for two-phase evaporation heat transfer coefficients of refrigerant R134a. They suggested the following correlation, retaining the basic form of the Kandlikar (1991) intube flow boiling correlation:

$$
h_{t p}=\left[2.312 \mathrm{Co}^{-0.3} E_{c b}+667.3 \mathrm{Bo}^{2.8} F_{f l} E_{n b}\right](1-x)^{0.003} h_{l o}
$$

where $F_{f l}$ is the fluid specific fitting parameter tabulated for the refrigerants tested. However, the authors mentioned this parameter can be put equal to 1 for other refrigerants, although without a database to prove this. The factors $E_{c b}$ and $E_{n b}$ are the multiplying enhancement factors to the convective boiling and nucleate boiling contributions, respectively. Fitting the correlation to the experimental data of Yan and Lin (1999), the values obtained were

$$
E_{c b}=0.512 \quad \text { and } \quad E_{n b}=0.338
$$

and the single-phase heat transfer coefficient was also modified to be applied within the above correlations, so that

$$
h_{l o}=0.2875 \operatorname{Re}_{l o}^{0.78} \operatorname{Pr}_{l}^{1 / 3} k_{l} / d_{h}
$$

However, according to the results presented in Yan and Lin (1999), their correlation proposed for single-phase water-to-water heat transfer is in fact in agreement with their single-phase data, which is contradictory to that observed and concluded by Donowski and Kandlikar (2000). Nevertheless, large discrepancies are found between the two-phase heat transfer data and the proposed prediction method for the evaporation heat transfer coefficient.

Hsieh and Lin (2002) performed experiments on saturated flow boiling of R410A in a vertical PHE of $60^{\circ}$ chevron angle and $3.3 \mathrm{~mm}$ corrugation depth. The effects of vapor quality, mass flow rate, heat flux, and system pressure on the evaporation heat transfer and pressure drop were investigated in detail. They suggested the following correlation to predict their mean heat transfer coefficients data of R410A:

$$
h_{t p}=h_{l o}\left(88 \mathrm{Bo}^{0.5}\right)
$$

The liquid-only heat transfer coefficient $h_{l o}$ is determined from an empirical correlation obtained through the single-phase water-to-water tests:

$$
h_{l o}=0.2092\left(\frac{k_{l}}{d_{h}}\right) \operatorname{Re}_{l o}^{0.78} \operatorname{Pr}_{l}^{1 / 3}\left(\frac{\mu_{l}}{\mu_{w}}\right)^{0.14}
$$

However, a Chen-type correlation was proposed later by Hsieh and Lin (2003) in order to predict the local saturated flow boiling data of R410A:

$$
h_{t p}=h_{p o o l} S+h_{l o} E
$$

where $h_{l o}$ and $h_{\text {pool }}$ are, respectively, given by the Dittus-Boelter correlation and the Cooper (1984) pool boiling correlation:

$$
\begin{gathered}
h_{l o}=0.023 \operatorname{Re}_{l o}^{0.8} \operatorname{Pr}_{l}^{0.4}\left(k_{l} / d_{h}\right) \\
h_{\text {pool }}=55 p_{r}^{0.12}\left(-\log _{10} p_{r}\right)^{-0.55} M^{-0.5} q^{0.67}
\end{gathered}
$$

The term $S$ represents the nucleate boiling suppression factor and the term $E$ the convective boiling enhancement factor. These terms are dependent on the Boiling number Bo, the Lockhart-Martinelli parameter X, and liquid-only Reynolds number $\operatorname{Re}_{l o}$ :

$$
\begin{gathered}
E=1+24,000 \mathrm{Bo}^{1.16}+1.37\left(\frac{1}{\mathrm{X}_{t t}}\right)^{0.86} \\
S=\left(1+1.15 \times 10^{-6} E^{2} \operatorname{Re}_{l o}^{1.17}\right)^{-1}
\end{gathered}
$$


Han et al. (2003) performed flow boiling experiments with refrigerants R410a and R22 in PHEs with chevron angles of $45^{\circ}, 55^{\circ}$, and $70^{\circ}$ and corrugation pitches of 7, 5.2, and $4.9 \mathrm{~mm}$. They correlated their two-phase Nusselt numbers data with respect to equivalent boiling and Reynolds numbers as well as some geometric parameters:

$$
\mathrm{Nu}=\mathrm{Ge}_{1} \mathrm{Re}_{e q}^{\mathrm{Ge} 2} \mathrm{Bo}_{e q}^{0.3} \operatorname{Pr}^{0.4}
$$

where the geometric parameters are defined as

$$
\mathrm{Ge}_{1}=2.81\left(\frac{\Lambda}{d_{h}}\right)^{-0.041}\left(\frac{\pi \beta}{180}\right)^{-2.83}, \mathrm{Ge}_{2}=0.746\left(\frac{\Lambda}{d_{h}}\right)^{-0.082}\left(\frac{\pi \beta}{180}\right)^{0.61}
$$

in which $\mathrm{Re}_{e q}$ and $\mathrm{Bo}_{e q}$ were defined such as in Akers et al. (1959):

$$
\operatorname{Re}_{e q}=\frac{G_{e q} d_{h}}{\mu_{l}} \text { and } \mathrm{Bo}_{e q}=\frac{q}{G_{e q} i_{l v}}
$$

where the equivalent mass flux is defined as

$$
G_{e q}=G\left[(1-x)+x\left(\rho_{l} / \rho_{v}\right)^{0.5}\right]
$$

Jokar et al. (2006) analyzed the thermo-hydrodynamic performance of three PHEs, different in size (number of flow passages) but with similar plate geometry specifications. Their average heat transfer and pressure drop data for complete evaporation were correlated using the dimensional analysis technique, given as

$$
\mathrm{Nu}_{t p}=0.603 \operatorname{Re}_{l o}^{0.5} \operatorname{Pr}_{l}^{0.1} x^{-2}\left(\frac{G^{2}}{\rho_{l}^{2} c_{p, l} \Delta T_{s a t}}\right)^{-0.1}\left(\frac{\rho_{l}^{2} i_{l v}}{G^{2}}\right)^{-0.5}\left(\frac{\rho_{l} \sigma}{\mu_{l} G}\right)^{1.1}\left(\frac{\rho_{l}}{\rho_{l}-\rho_{v}}\right)^{2}
$$

Táboas et al. (2010) conducted experimental work on the saturated flow boiling heat transfer and associated frictional pressure drops of ammonia/water mixtures flowing in a $60^{\circ}$ chevron angle PHE. Later, Táboas et al. (2012) assessed several boiling heat transfer and pressure drop correlations. Based on that, a modified flow boiling correlation was also proposed as follows:

$$
\begin{gathered}
h_{t p}=5 \mathrm{Bo}^{0.15} h_{l o} \\
\text { the greater of } \begin{cases}h_{n b}=5 \mathrm{Bo}^{0.15} h_{l o} & J_{v}<-111.88 J_{l}+11.848 \\
h_{c b}=\left(\varphi_{l}^{2}\right)^{0.2} h_{l o} & J_{v}>-111.88 J_{l}+11.848\end{cases}
\end{gathered}
$$

where

$$
F=\left(\varphi_{l}^{2}\right)^{0.2}=\left(1+\frac{C}{\mathrm{X}_{t t}}+\frac{1}{\mathrm{X}_{t t}^{2}}\right)^{0.2}
$$

and $J_{l}$ and $J_{v}$ were the superficial velocities of the liquid and vapor phases, respectively.

In addition, the correlation of Kumar (1984) was chosen to be used to predict the single-phase heat transfer coefficient $h_{l o}$ and the following correlation was suggested to predict the single-phase pressure drop data:

$$
f_{s p}=4.779 \mathrm{Re}^{-0.118}
$$

Despite worthwhile studies, most of the previous studies measured mean heat transfer coefficients for the entire plate, not local values needed for proposing a local prediction method and for extending the fundamental understanding of flow boiling phenomena within PHEs. As a consequence, in the present study on a more compact PHE, having a pressing depth of $1 \mathrm{~mm}$, a chevron angle $65^{\circ}$, and a thinner plate of only $0.15 \mathrm{~mm}$, these aspects will here be experimentally investigated. This study aims at extending the knowledge of local flow boiling heat transfer in PHEs and creation of a database for evaluating and updating the heat transfer prediction methods. Accordingly, a thermal camera has been used to measure the plate surface temperatures with high resolution and then the data were reduced to obtain the local pixel-by-pixel, in addition to the mean, flow boiling heat transfer coefficients within the PHE. 


\section{EXPERIMENTAL SETUP AND PROCEDURE}

\subsection{Test Facility}

The test facility has already been described in Part I of this study, specifically to investigate high-resolution local evaporation heat transfer and pressure drops of R245fa within a more compact PHE prototype. This low-pressure refrigerant was chosen as being compatible with the plates being only welded together around their perimeter and held tightly together by a frame. The test section (evaporator) was composed of two extremely thin corrugated stainless steel plates making single-pass inter-plate channels. All dimensions of the test section are given in Table 1 of Part I. A DC power supply (Sorensen DCS8-125E) was used to apply electrical current directly into the plates, providing uniform heat distribution. Accordingly, the dielectric heat transfer fluid (R245a) was evaporated as it flowed between the two plates electrically heated. Moreover, a PVC frame box was designed to enclose, support and insulate the plates during the operating conditions. Furthermore, a thermographic infrared (IR) camera from FLIR (Therma-CAM SC 3000) was set up to measure the local wall temperatures for the plate from one side. For further details, refer to Part I.

\subsection{PHE Test Section}

The test section was designed to perform a thermal visualization of the fluid flow as well as locally investigate twophase adiabatic pressure drops and flow boiling phenomena all around the plate. Therefore, a single-pass refrigerant flow passage PHE was made. Electrical current from a DC power supply (Sorensen DCS8-125E) was directly applied into the plates in order to mimic evaporation in a PHE. Although the plate is uniformly heated in this approach, nevertheless, it allows us to measure the local plate surface temperatures pixel-by-pixel. However, the electrical resistance of the plates was found to be rather small $(<1 \Omega)$, and thus a relatively high current was required to apply the desired input power. Therefore, appropriate cables with very low electrical resistance were selected to minimize power loss through the wires. Later, single-phase tests were conducted just prior to the two-phase experiments in order to calibrate and account for these losses. The cables were also attached to the plates using two clamps (shown in Fig. 1). Finally, the test section was coated with high-emissivity black paint and enclosed by a box to avoid any undesired disturbances (e.g., irradiation or reflection from/to the surrounding objects).

\subsection{Measurement Systems: Calibration and Accuracy}

The measurement systems and calibrations were all presented earlier in Part I. Most of the heat provided by the DC power supply is delivered to the refrigerant flow. A series of single-phase tests (remaining a turbulent refrigerant flow condition) was conducted first to calibrate the heat losses in the preheater and the test section (the PHE prototype). Accordingly, the heat and mass fluxes were changed in order to survey the energy balance between refrigerant flow and electrical input power. The difference was realized as the total loss:

$$
Q_{\text {loss }}=V I-\dot{m} c_{p}\left(T_{\text {refg,out }}-T_{\text {refg, in }}\right)
$$

The heat loss was deduced to be only a function of wall surface temperature for the preheater (see Fig. 6 in Part I). However, for the PHE, a quadratic dependence to the applied electrical current was observed that was linked to different sources of the heat losses in this case (shown in Fig. 2). In fact, for the PHE, relatively much higher electrical currents were applied in order to provide the desired heat flux test condition (the plate electrical resistance

TABLE 1: Summary of total uncertainty analysis of the results

\begin{tabular}{|c|c|c|}
\hline Parameter & Range in tests & Total uncertainty \\
\hline Heat flux [ $\left.\mathrm{W} \mathrm{m}^{-2}\right]$ & $250-3700$ & $0.5-2.5 \%$ \\
\hline Vapor quality [-] & $0-0.8$ & $1-5 \%$ \\
\hline Single-phase heat transfer coefficient $\left[\mathrm{W} \mathrm{m}^{-2} \mathrm{~K}^{-1}\right]$ & $100-2000$ & $2-9 \%$ \\
\hline Two-phase heat transfer coefficient $\left[\mathrm{W} \mathrm{m}^{-2} \mathrm{~K}^{-1}\right]$ & $850-4000$ & $3-21 \%$ \\
\hline
\end{tabular}

Volume 2, Number 4, 2014 


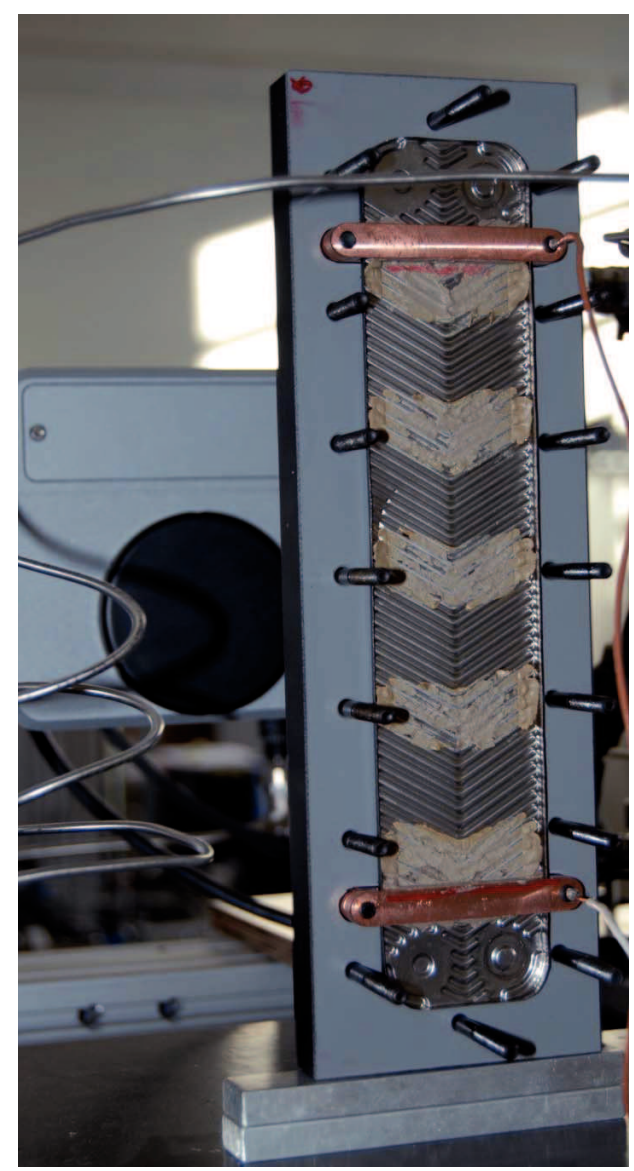

FIG. 1: Photograph of the test section setup on the facility before closing the frame

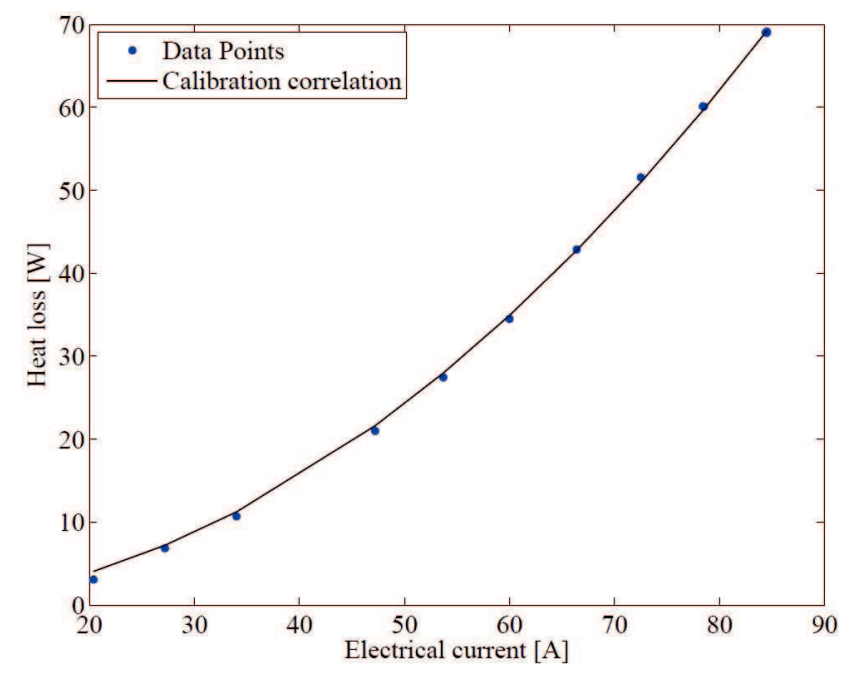

FIG. 2: Heat loss through the cables and connections in PHE correlated with applied electrical current 
was very small) and thus the main losses were determined to be through the cabling and connections; the relative heat losses through conduction and natural convection to the surrounding were negligible. Therefore, the heat losses in the preheater and PHEs were correlated with respect to the appropriate parameters. The results were then used later to determine the actual power delivered to the refrigerant flow through the two-phase experiments.

\subsection{Uncertainty Analysis}

The uncertainty analysis presented in Part I is also applied to the diabatic test results here. Table 1 presents the total uncertainty and error propagation for the test results. The primary contribution to experimental uncertainty of the two-phase heat transfer coefficients was due to the uncertainty associated with the wall to saturation temperature difference. The other components of the overall uncertainty were associated with the heat flux, the plate hydraulic diameter, and the refrigerant mass flow rate.

\section{DATA REDUCTION}

In the present study, a new experimental approach (it has not yet been applied to PHEs) was introduced in order to investigate high-resolution local evaporation heat transfer of R245fa within the compact prototype PHE while the two-phase frictional pressure drop data were presented and discussed in Part I. Several small openings were created in one side of the frame in order to have IR camera access to measure local pixel-by-pixel plate surface temperatures using a thermographic/infrared camera. To emulate the evaporation process within the PHE, electrical current from a DC power supply was applied directly into the two plates. Although the PHE was uniformly heated in this approach, nevertheless, the setup allowed measuring of the local plate surface temperatures pixel-by-pixel. In a real PHE with multistream flow passages, the heat flux distribution is more or less uniform while boiling occurs over its entire length; nevertheless, it becomes nonuniform as a dryout regime prevails (Vakili-Farahani et al., 2013).

\subsection{Single-Phase Heat Transfer Analysis}

In the present experimental setup, refrigerant temperatures were measured by the thermocouples at the inlet and outlet of the PHE, whereas local wall temperatures along the plate were measured using a thermal camera. As the heat fluxes were low and the plate thickness thin $(0.15 \mathrm{~mm})$, the temperature drop from its outside to inside surface was small, less than the accuracy of the IR temperature measurement itself. The heat loads were applied directly to the PHE utilizing a DC power supply and thus the corresponding effective heat fluxes, $q$, were quantified as the total heat delivered to the refrigerant:

$$
Q_{e f f}=\dot{m} c_{p}\left(T_{\text {refg,out }}-T_{\text {refg,in }}\right)
$$

Therefore, mean heat transfer coefficients (all pixels in all six windows over the plate) were determined as

$$
h_{\text {refg,mean }}=\frac{q}{T_{\text {wall,mean }}-T_{\text {refg,mean }}}
$$

where the wall temperature measurements from the IR camera and refrigerant temperatures (at the PHE inlet and outlet) were averaged to evaluate the mean wall and refrigerant temperatures, respectively.

However, Eq. (20) was used once more to determine the local pixel-by-pixel single-phase heat transfer coefficients using the corresponding local wall and refrigerant temperatures:

$$
h_{\text {refg,pixel }}=\frac{q}{T_{\text {wall,pixel }}-T_{\text {refg,pixel }}}
$$

In this case, the wall temperature of each pixel was measured directly using the IR camera. As the PHE wall imposed to a uniform heat flux, the local refrigerant temperatures changed linearly along the flow direction and thus the local saturation temperature can be determined as follows:

$$
T_{\text {refg }}(z)=T_{i n}+\frac{Q_{e f f}}{\dot{m} c_{p} L} z
$$




\subsection{Two-Phase Heat Transfer Analysis}

The flow boiling heat transfer data were reduced in three different manners in order to determine mean, local, and quasi-local two-phase heat transfer coefficients. The flow boiling mean heat transfer coefficients within the PHE were obtained using Eq. (20), whereas the mean refrigerant temperatures were calculated averaging the inlet and outlet saturation temperatures. In addition, the corresponding effective heat flux was quantified after taking into account the losses through the electrical cables and connections. Accordingly, the corresponding mean vapor quality was given as

$$
x_{m}=\frac{x_{\text {out }}+x_{\text {in }}}{2}
$$

while the inlet and outlet vapor qualities were calculated as follows:

$$
\begin{gathered}
x_{i n}=\frac{\dot{m}_{r e f g} c_{p}\left(T_{r e f g, i n}-T_{r e f g, s a t}\right)}{\dot{m}_{r e f g} i_{l v}} \\
x_{\text {out }}=x_{\text {in }}+\frac{Q_{e f f}}{\dot{m}_{r e f g} i_{l v}}
\end{gathered}
$$

However, a series of flow boiling experiments has been performed with two-phase liquid/vapor flow at the inlet $\left(\mathrm{x}_{i n} \approx 0.1-0.2\right)$ of PHE. In this case, boiling was initiated in the preheater instead of PHE and thus the energy was balanced on the preheater to determine the inlet quality as follows:

$$
x_{i n}=\frac{\dot{m}_{r e f g} c_{p}\left(T_{\text {refg,in,preheater }}-T_{\text {sat }, \text { in }}\right)+(V I)_{\text {preheater }}-Q_{\text {loss }, \text { preheater }}}{\dot{m}_{\text {refg }} i_{l v}}
$$

Similarly, the local flow boiling heat transfer coefficients within the PHE were evaluated using Eq. (21), whereas the local refrigerant temperatures were determined according to the two-phase pressure drop analysis that had been obtained earlier from adiabatic two-phase experiments (presented in Part I). According to the observation during the adiabatic two-phase pressure drop tests, neither a linear pressure drop nor even a two-phase pressure drop scheme (e.g., an existing prediction method from the PHE's literature) was found to be applicable to estimate the correct trend of the pressure field in the PHE since effects of outlet restriction and flow collector on pressure field were realized to be considerable. Therefore, the frictional pressure drops within the PHE were correlated individually for each consecutive opening (from the inlet to the outlet) based on the data obtained from IR measurements during adiabatic two-phase tests covering the applicable range of flow boiling tests.

Figure 3 displays the pressure fields and a comparison of the heat transfer coefficients based on different assumptions for determining the local saturation pressure/temperature for reducing the data: (i) the linear pressure drop, (ii) using the Yan and Lin (1999) method for frictional pressure drop, (iii) the new expression in Part I, Eq. (23), and (iv) the two-phase adiabatic pressure drop results at a designated flow boiling test condition. As expected, using the three prediction methods led to the local refrigerant pressure profile dropping continuously from the inlet to the outlet since the outlet effect on the pressure profile (pressure field) within the PHE was not included in any of the prediction methods. However, the pressure profile predicted based on the adiabatic two-phase test results involved influences of the outlet restriction and flow collector on the pressure profile and thus led to a good match with the former observation (presented in Part I) through the adiabatic two-phase experiments. The sensitivity of obtaining the local saturation pressures from the local pixel temperatures is also a factor here. Based on this situation, the best choice is to use the two-phase adiabatic test results to get the local saturation temperature for calculating the local heat transfer coefficient. Note that the choice of method does not influence the heat transfer coefficients near the inlet (the lower vapor qualities) but does change the others; the first three methods in fact predict a maximum and then decrease in the local heat transfer coefficient with rising vapor quality, which is quite unexpected, while the local pressure method does not. More details of the test results will be discussed below.

For each flow boiling test condition, the two-phase pressure field was calculated based on the result of previous adiabatic two-phase pressure drop tests. Therefore, local refrigerant temperatures were determined from the corresponding saturation pressures (since boiling was initiated):

$$
T_{\text {refg,pixel }} \propto p_{\text {sat,pixel }}
$$




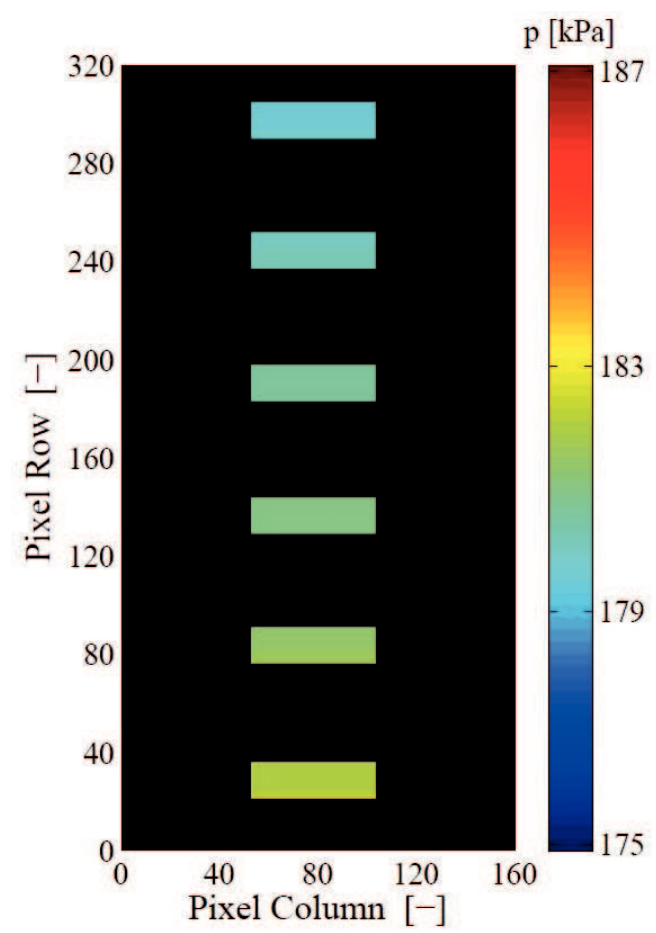

(a)

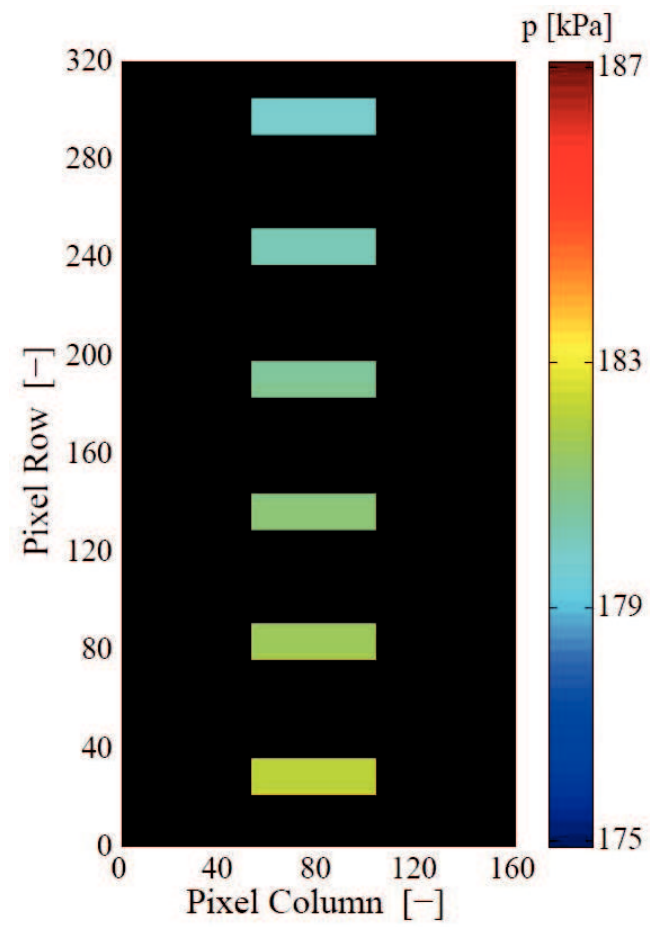

(c)

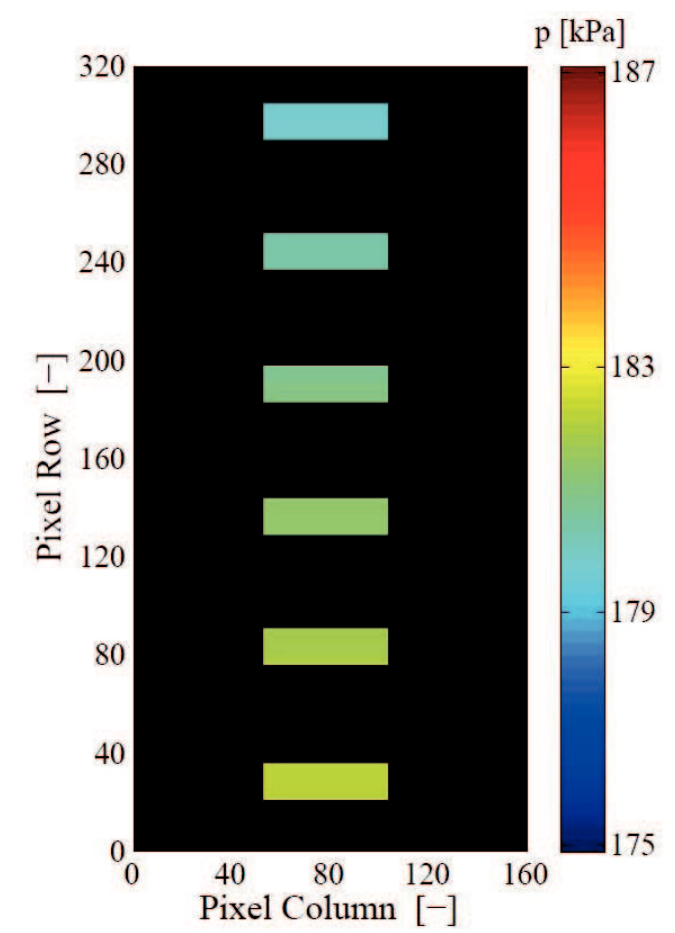

(b)

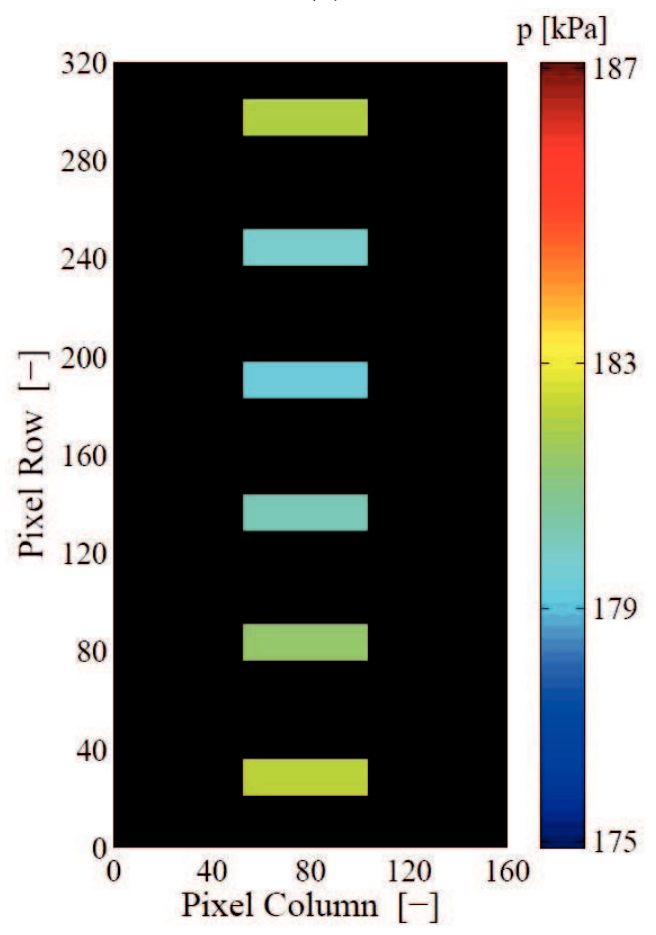

(d)

FIG. 3 


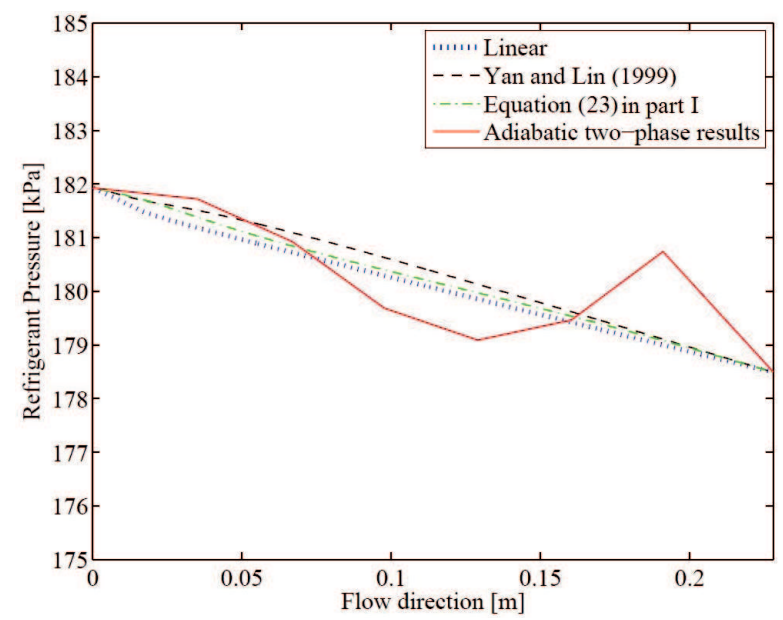

(e)

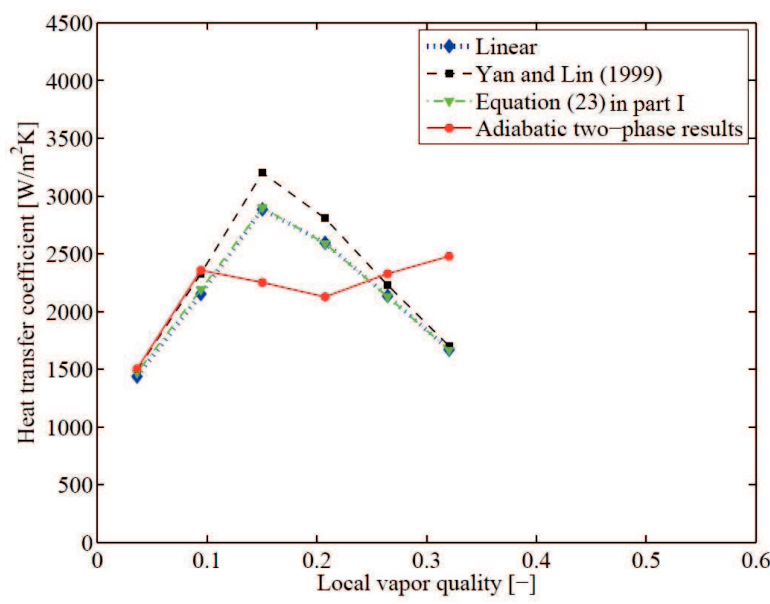

(f)

FIG. 3: Sample of refrigerant pressure field/profile obtained for the flow boiling test condition of $\mathrm{G}=10 \mathrm{~kg} \mathrm{~s}^{-1} \mathrm{~m}^{-2}$, $\mathrm{q}=1800 \mathrm{~W} \mathrm{~m}^{-2}$, and $\mathrm{T}_{\text {sat }}=30^{\circ} \mathrm{C}$ in accordance with the pressure drop scheme presumption: (a) linear; (b) Yan and Lin (1999); (c) proposed model in part I [Eq. (23) in part I]; (d) two-phase adiabatic results correlated for each consecutive opening; (e) comparison in terms of the pressure profile; and (f) comparison of quasi-local flow boiling heat transfer coefficients

while for the subcooled region (i.e., two-phase tests with subcooling at the inlet, $\mathrm{x}_{\text {in }}<0$ ) the liquid refrigerant temperature was computed by integrating the heat flux along the length:

$$
T_{r e f g}(z)=T_{r e f g, i n}+\frac{\int_{0}^{z} q_{r e f g}(z) P_{i} d z}{\dot{m}_{r e f g} c_{p}}
$$

Consequently, the local vapor quality of the refrigerant flow was defined as follows:

$$
x(z)=x_{i n}+\frac{\int_{0}^{z} q_{r e f g}(z) P_{i} d z}{\dot{m}_{r e f g} i_{l v}}
$$

Mean heat transfer coefficients on the six openings for each test condition were calculated based on the averaged wall and refrigerant temperature at every individual "window" and termed here as quasi-local flow boiling heat transfer coefficients. Note that all the individual pixel heat transfer coefficients could be presented here, but they effectively form a "dense cloud" around the window's mean value and hence are not shown for clarity's sake. The experimental results are presented in the following section, in which the prediction methods are first evaluated against the mean data and then compared to the quasi-local heat transfer coefficients.

\section{RESULTS AND DISCUSSION}

\subsection{Single-Phase Heat Transfer: Results and Predictions}

The experimental single-phase mean Nusselt numbers were compared to several existing PHE prediction methods in Fig. 4. As observed in this figure, the Kovalenko and Maslov (1970) correlation was found to be in a good agreement with the present results, while several other methods matched reasonably well to turbulent flow regime data but showed 


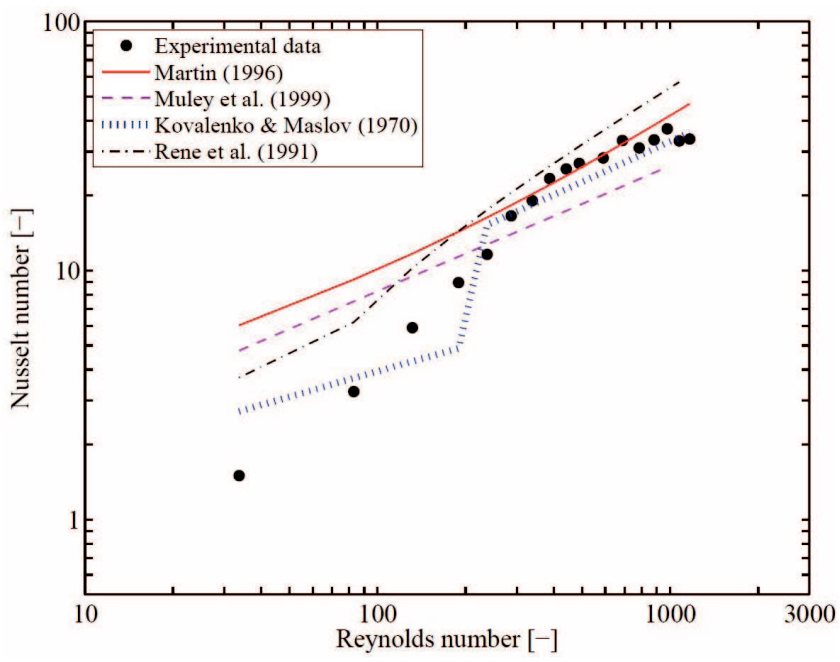

FIG. 4: Single-phase experimental Nusselt numbers compared to the prediction methods

an overprediction on laminar flow regime data. All of these methods were extrapolations to the smaller corrugation height of $1 \mathrm{~mm}$ here.

Next, the local single-phase data from the IR camera have been reduced in order to establish a meticulous attention to the local single-phase heat transfer performance within the PHE. Figure 5 displays examples of the single-phase heat transfer coefficient map obtained for the specific test conditions. Notably, the higher heat transfer coefficients were obtained on the left side, where the inlet and outlet ports lie on the same side. This creates a higher Reynolds number or flow turbulence on the left side than the right side, which can be linked primarily to flow acceleration at

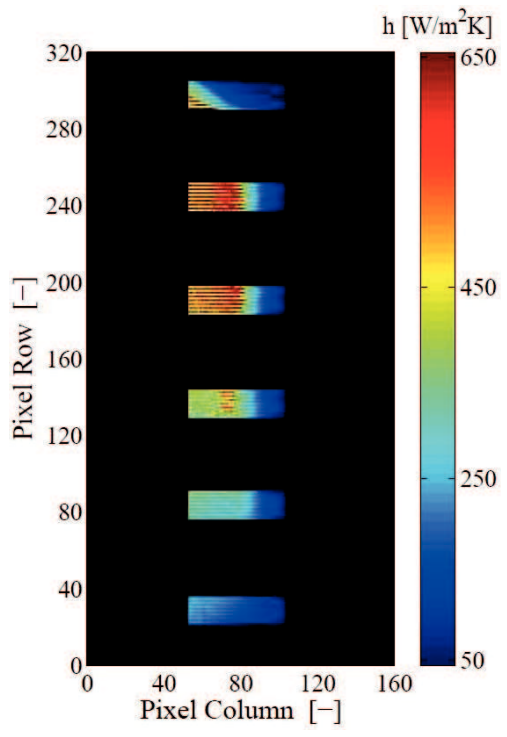

(a)

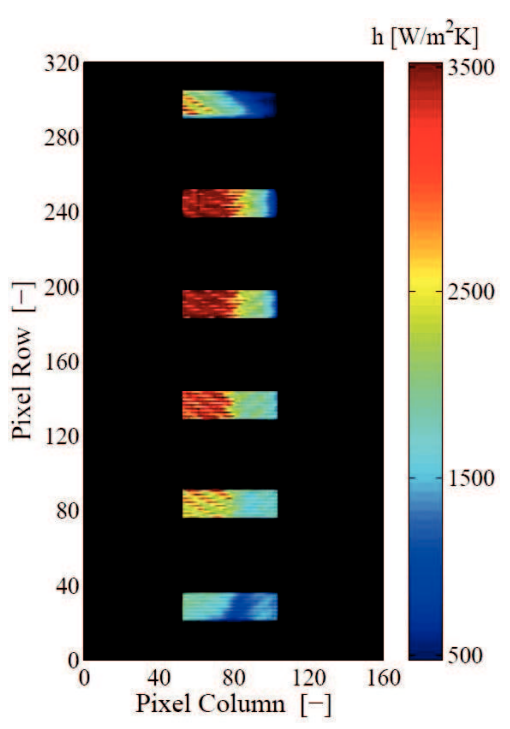

(b)

FIG. 5: Experimental single-phase heat transfer coefficient map obtained at (a) $\operatorname{Re}=83$ and $\mathrm{q}=340 \mathrm{~W} \mathrm{~m}^{-2}$, (b) $\mathrm{Re}$ $=1000$ and $\mathrm{q}=3500 \mathrm{~W} \mathrm{~m}^{-2}$ 
the exit and then to a shorter port-to-port traveling distance that is favorable for the flow stream. In general, this is a thermal aspect endemic of all plate designs.

\subsection{Flow Boiling Heat Transfer}

\subsubsection{Results and Discussion}

Upflow boiling heat transfer was investigated locally within the single-pass PHE using an IR camera to measure the local PHE wall temperatures with high resolution. Experimental tests were carried out first with small subcooling ( $\mathrm{T}_{\text {refg,in }}<1 \mathrm{~K}$ and thus $\mathrm{x}_{\text {in }}<0$ ) and later repeated with two-phase flow at the inlet $\left(\mathrm{x}_{\text {in }} \approx 10-20 \%\right.$, which is customary in refrigeration applications). Different refrigerant flow rates were tested, ranging from 7.5 to $40 \mathrm{~kg} \mathrm{~m}^{-2} \mathrm{~s}^{-1}$. The heat loads were provided by an electrical supply and applied directly into the PHE, yielding heat fluxes from 250 to $3700 \mathrm{~W} \mathrm{~m}^{-2}$. Also, the nominal saturation temperatures were changed from $19^{\circ} \mathrm{C}$ to $35^{\circ} \mathrm{C}$ to include this influence in the resulting database. Experiments were performed in such a way that the effects of heat flux, vapor quality, saturation pressure/temperature, and mass flux could be studied.

As it was explained earlier, the flow boiling data were reduced in three different manners to obtain the corresponding mean, local (pixel-by-pixel), and quasi-local "window" (six locations along the flow direction) heat transfer coefficients. Figures 6(a) and 6(b) present two samples of local pixel-by-pixel flow boiling heat transfer coefficients (as a map) for the designated conditions with small subcooling at the inlet. The corresponding quasi-local "window" heat transfer coefficients were also depicted in Figs. 6(c) and 6(d). As can be seen, the subcooled liquid flow enters the PHE and thus a subcooled boiling zone with lower heat transfer coefficient than saturated boiling is established around the inlet port. Then, relatively uniform and higher heat transfer rates are obtained later once saturated flow boiling is initiated. This subcooled boiling zone was minimized at higher heat fluxes since saturated boiling started earlier.

Another example of flow boiling heat transfer results with two-phase flow at the inlet is represented in Fig. 7 for similar test conditions as plotted in the previous figure but with a two-phase inlet condition. Notably, a more uniform flow and heat transfer rate was observed here for the condition with around $10-20 \%$ vapor quality at the inlet since a subcooled boiling zone does not exist. This condition is favorable as it maximizes the thermal performance of the PHE by extending the saturated boiling zone, but nevertheless the higher associated pressure drops need to be accommodated. The heat transfer data for the two-phase inlet are the same or slightly higher (about 0-15\%) compared to the subcooling data at similar local test conditions.

In Fig. 8, the mean flow boiling heat transfer coefficients and relevant pressure drops for one set of experiments (change of heat flux and thus outlet vapor quality) with subcooling at inlet are compared to similar test conditions with two-phase flow at the inlet. As explained earlier, the mean flow boiling heat transfer coefficients and associated pressure drops were slightly higher for the test conditions with two-phase flow than subcooled liquid at the inlet. While the nonzero vertical axis on the left appears to show otherwise at first glance, the results for both the frictional pressure drops and heat transfer coefficients are quite comparable where they overlap in outlet vapor quality.

The influences of mass flux, heat flux, system pressure (saturation temperature), and vapor quality on the mean and quasi-local flow boiling heat transfers were examined as follows. The results were typically similar to those observed for intube flow boiling. Figure 9 illustrates the effect of saturation temperature on the quasi-local flow boiling heat transfer coefficients. In general, the effect of saturation pressure or accordingly the evaporating temperature on the flow boiling heat transfer was found to be significant over the whole range of vapor quality. Basically, the latent heat of vaporization decreases with increasing saturation temperature so that the liquid film has to evaporate more refrigerant to dissipate the heat flux, and the resulting thinner liquid film offers the higher heat transfer coefficients. Furthermore, the thermal conductivity of the refrigerant increases with increasing the saturation temperature and this promotes the heat transfer rate.

Figure 10 shows the effect of heat flux on the quasi-local saturated flow boiling heat transfer coefficients with refrigerant R245fa. The heat transfer coefficient typically increases with increasing heat flux. The effect of mass flux on the heat transfer coefficient is presented in Fig. 11. First, the heat transfer coefficients tend to increase slightly with mass flux, indicating that convective boiling is influential. Secondly, the enhancement of the heat transfer coefficient 


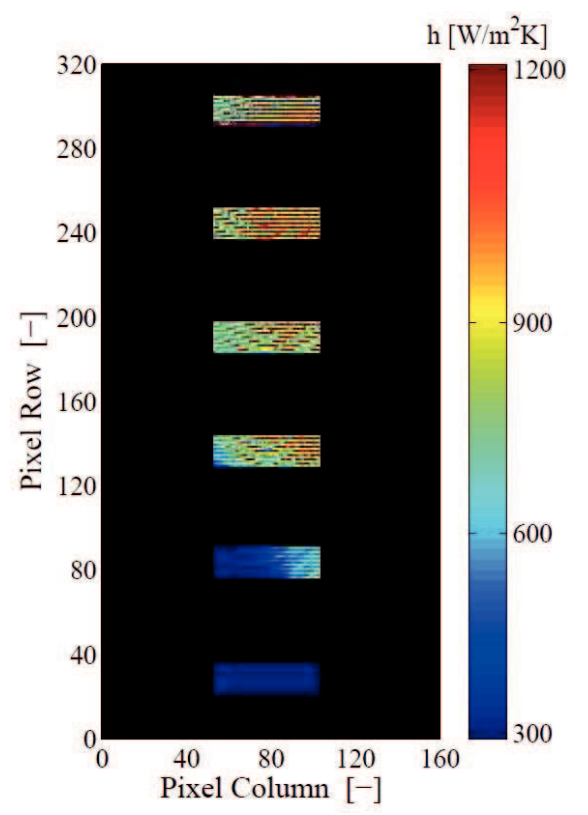

(a)

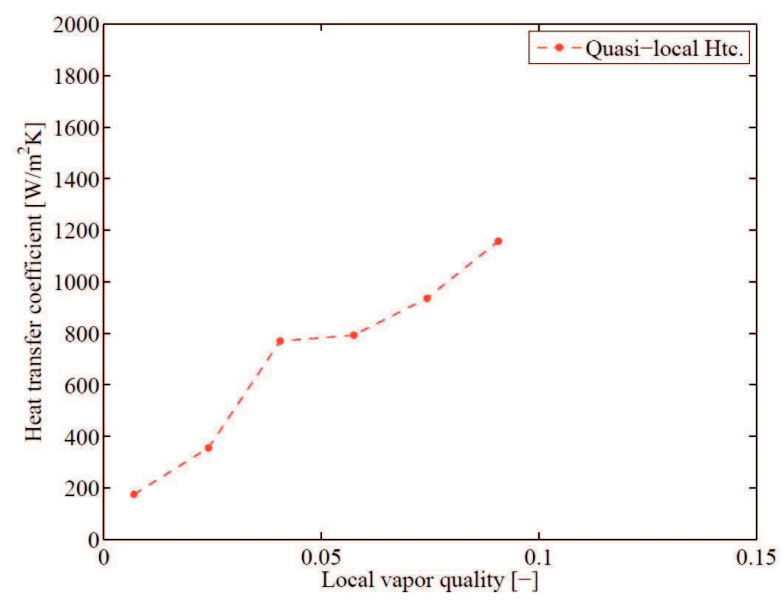

(c)

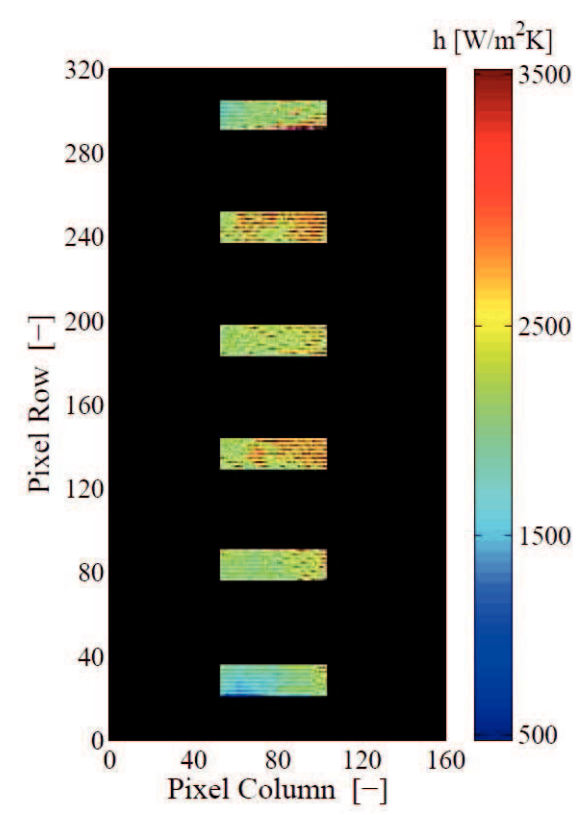

(b)

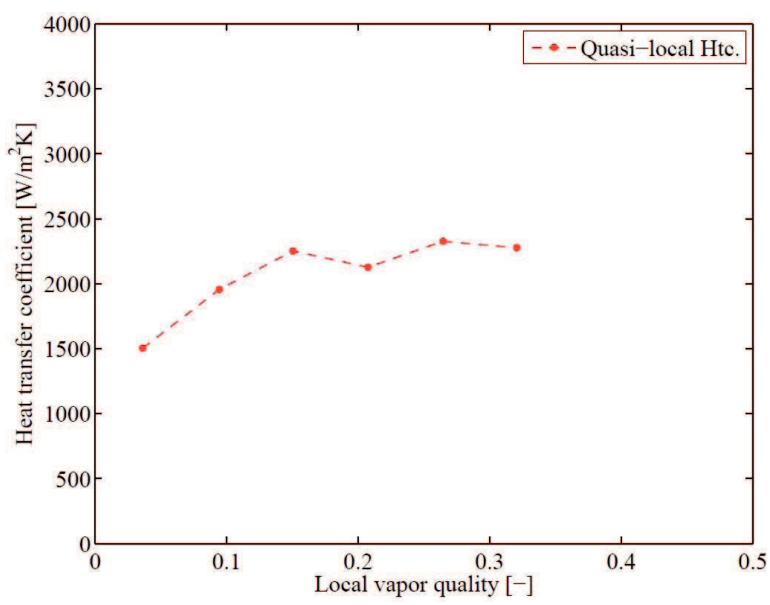

(d)

FIG. 6: Sample of flow boiling heat transfer coefficient map for the condition with small subcooling $\left(\mathrm{T}_{\text {sub }} \approx 0.5^{\circ} \mathrm{C}\right)$ at the PHE inlet and (a) $\mathrm{G}=10 \mathrm{~kg} \mathrm{~m}^{-2} \mathrm{~s}^{-1}, \mathrm{~T}_{\text {sat }}=30^{\circ} \mathrm{C}, \mathrm{q}=500 \mathrm{~W} \mathrm{~m}^{-2}$, (b) $\mathrm{G}=10 \mathrm{~kg} \mathrm{~m}^{-2} \mathrm{~s}^{-1}, \mathrm{~T}_{\text {sat }}=30^{\circ} \mathrm{C}, \mathrm{q}=$ $1700 \mathrm{~W} \mathrm{~m}^{-2}$, and the respective quasi-local heat transfer coefficients depicted in (c) and (d) for the six windows

becomes minimal at the low qualities, where isolated/coalescing bubbly regimes are expected, and the values converge approximately on the same magnitude attributed to the onset of boiling. Similar results were also reported in Yan and Lin (1999), Hsieh and Lin (2002), Hsieh and Lin (2003), Djordjevic and Kabelac (2008), and Khan et al. (2014).

\subsubsection{Comparison with Prediction Methods}

In the previous section, the flow boiling heat transfer coefficients data were presented. The present experimental results address the local flow boiling heat transfer coefficients using an IR camera to measure the wall temperatures 


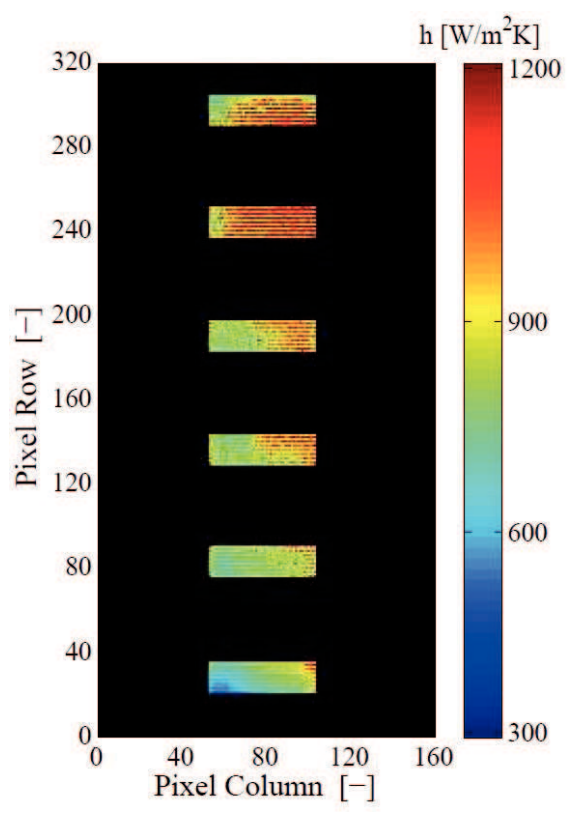

(a)

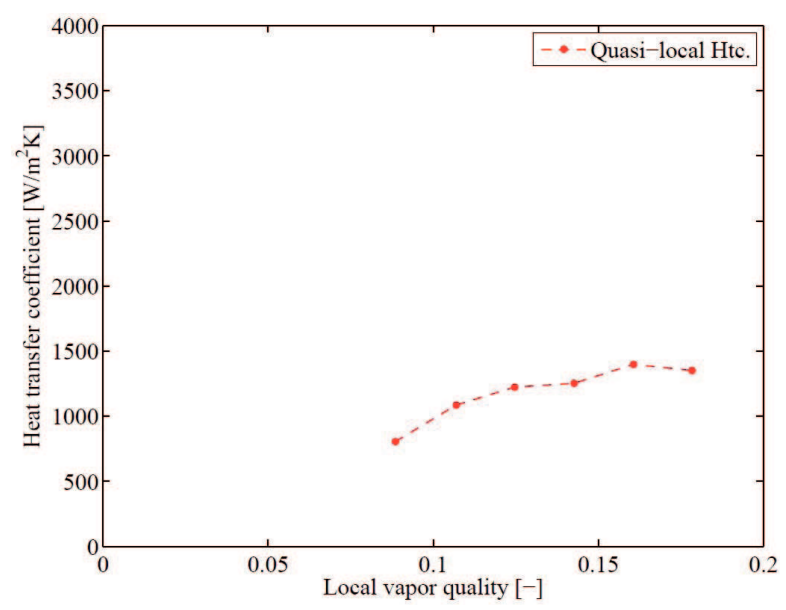

(c)

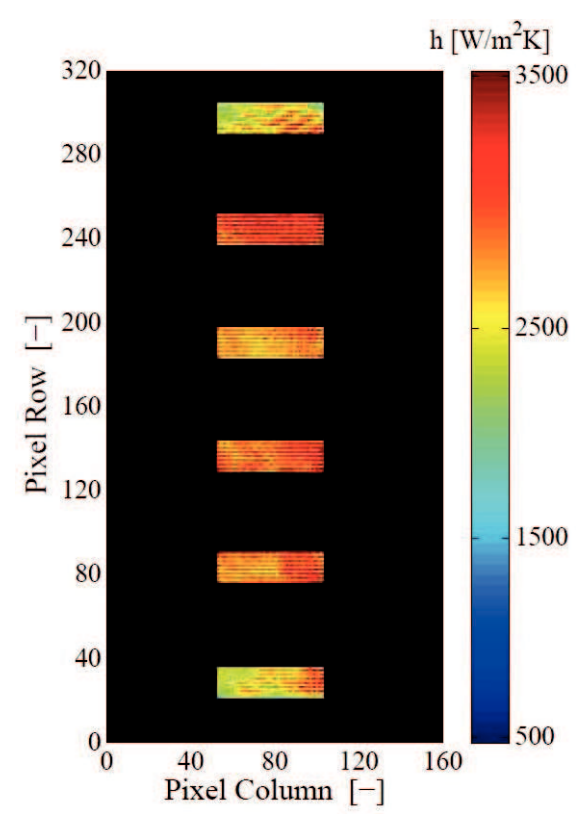

(b)

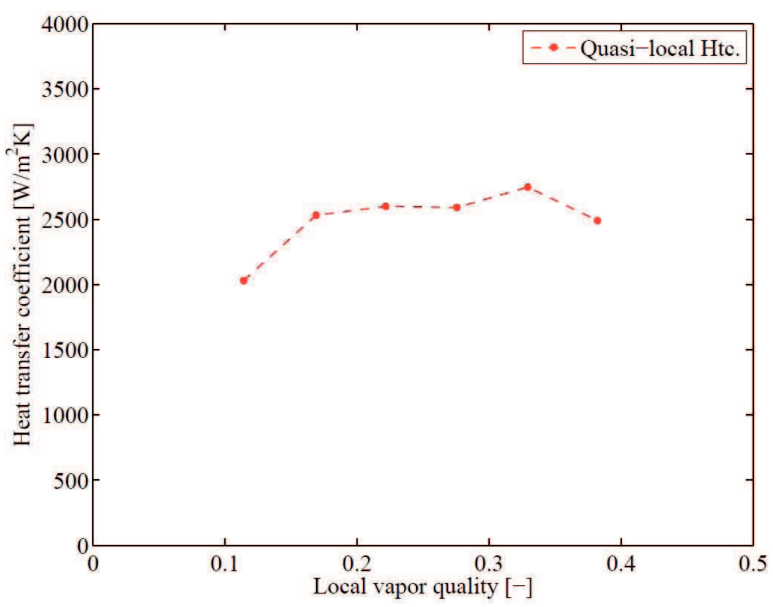

(d)

FIG. 7: Sample of flow boiling heat transfer analysis with two-phase flow at the PHE inlet $\left(\mathrm{x}_{i n}=0.08\right)$; heat transfer coefficient map of test condition (a) $\mathrm{G}=10 \mathrm{~kg} \mathrm{~m}^{-2} \mathrm{~s}^{-1}, \mathrm{~T}_{\text {sat }}=30^{\circ} \mathrm{C}, \mathrm{q}=500 \mathrm{~W} \mathrm{~m}{ }^{-2}$, (b) $\mathrm{G}=10 \mathrm{~kg} \mathrm{~m}^{-2} \mathrm{~s}^{-1}$, $\mathrm{T}_{\text {sat }}=30^{\circ} \mathrm{C}, \mathrm{q}=1700 \mathrm{~W} \mathrm{~m}^{-2}$, and the respective quasi-local heat transfer coefficients of the six windows depicted in (c) and (d)

with high resolution. The flow boiling experimental data were reduced to obtained the mean (all over the plate) and the quasi-local "window" (obtained in six locations along the flow direction) heat transfer coefficients. All together, 165 mean flow boiling heat transfer coefficients data were obtained through the flow boiling experiments with R245fa while 990 quasi-local heat transfer coefficients data points were deduced.

Table 2 summarizes a statistical comparison of the experimental data points of flow boiling heat transfer coefficients against several of the most widely quoted prediction methods of the PHE literature, all of them being extrapolated to the $1 \mathrm{~mm}$ corrugation height here. In addition, a graphical comparison between the best prediction methods 


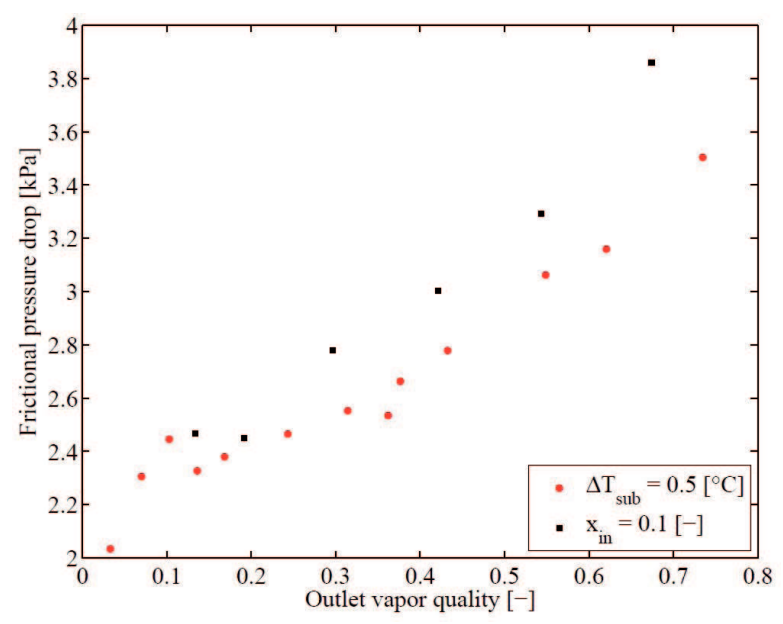

(a)

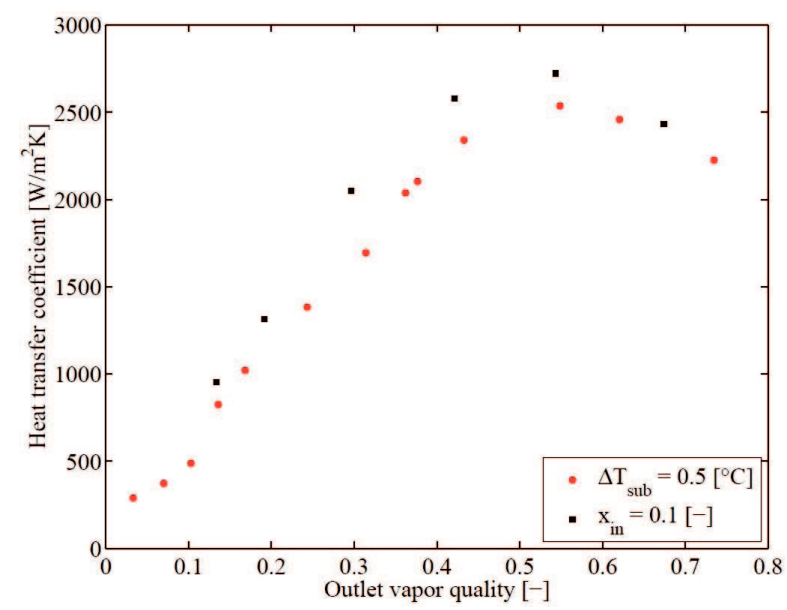

(b)

FIG. 8: Comparison between the results obtained with subcooling (red circles) and with two-phase flow at the inlet (black square) for the similar flow boiling test condition of $\mathrm{G}=10 \mathrm{~kg} \mathrm{~m}^{-2} \mathrm{~s}^{-1}, \mathrm{~T}_{\text {sat }}=25^{\circ} \mathrm{C}$ (a) frictional pressure drop; (b) mean heat transfer coefficients

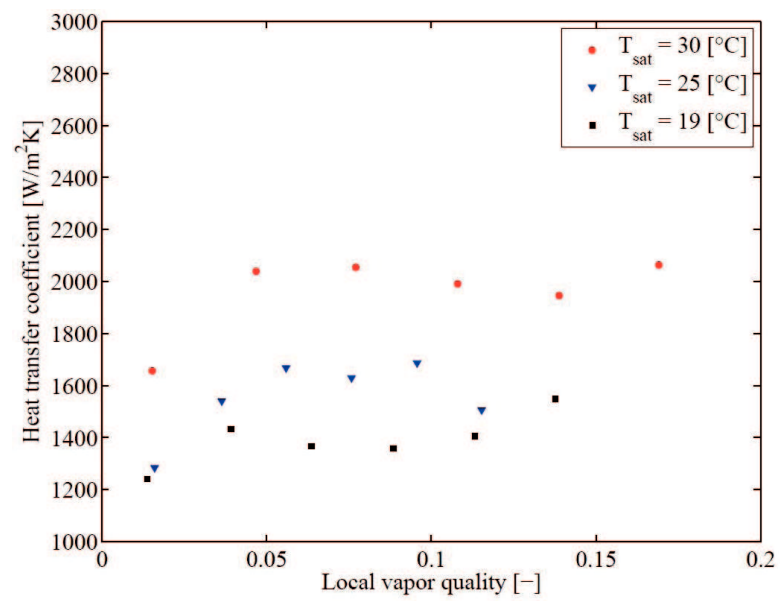

(a)

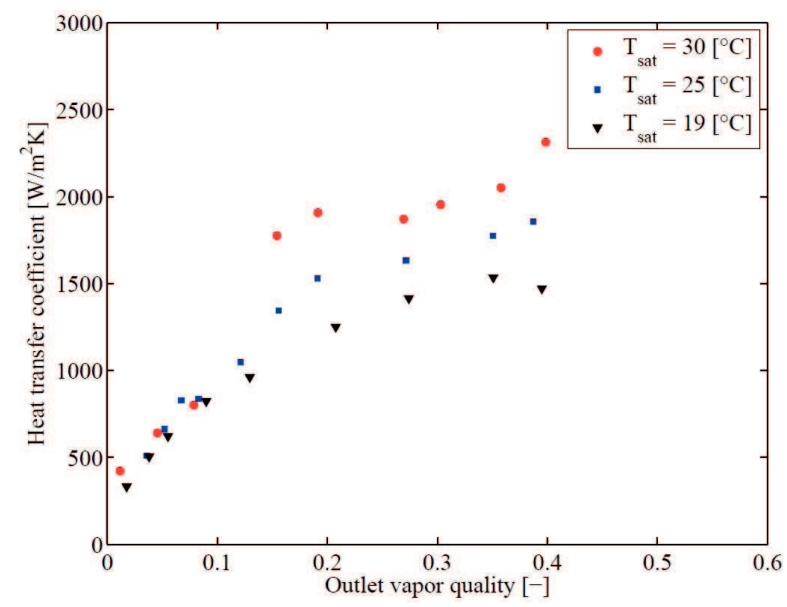

(b)

FIG. 9: Effect of saturation temperature on the (a) quasi-local flow boiling heat transfer coefficients at $\mathrm{G}=$ $20 \mathrm{~kg} \mathrm{~s}^{-1} \mathrm{~m}^{-2}$ and $\mathrm{q}=1500 \mathrm{~W} \mathrm{~m}^{-2}$ and (b) mean heat transfer coefficients obtained at $\mathrm{G}=20 \mathrm{~kg} \mathrm{~s}^{-1} \mathrm{~m}^{-2}$

and the present flow boiling heat transfer database is illustrated in Fig. 12. As can be observed, the prediction methods worked better for the mean heat transfer data as these methods were basically developed based on such mean heat transfer databases themselves and thus they may be disqualified for predicting the vapor quality trends in local (or quasi-local) heat transfer data.

In general, most of the prediction methods tended to overestimate the low values of the local heat transfer data (mostly pertinent to the low vapor qualities), while the higher local heat transfer coefficients were underestimated. This can be linked to their nature as they were originally developed according to the mean and not local heat transfer data (such mean data tend to give the local heat transfer coefficient at the midpoint vapor quality of such tests and 


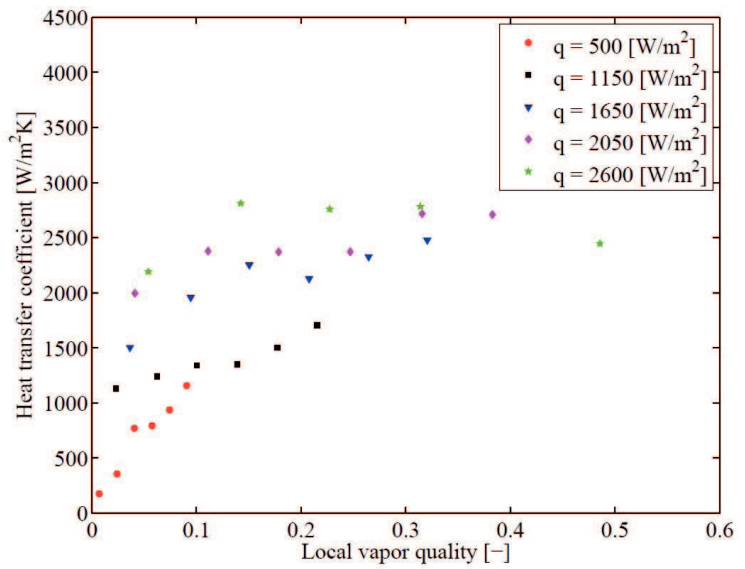

(a)

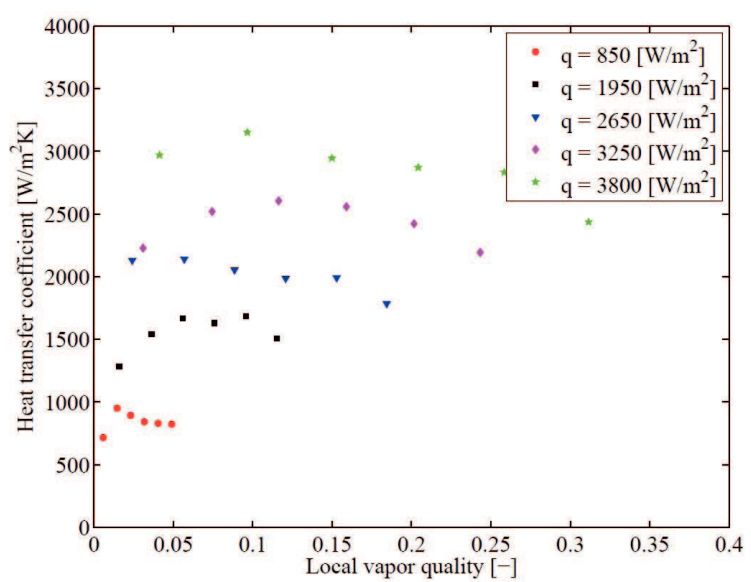

(b)

FIG. 10: Effect of heat flux on the quasi-local flow boiling heat transfer coefficients obtained at (a) $\mathrm{G}=10 \mathrm{~kg} \mathrm{~s}^{-1} \mathrm{~m}^{-2}$ and $\mathrm{T}_{\text {sat }}=30^{\circ} \mathrm{C}$ and (b) $\mathrm{G}=20 \mathrm{~kg}^{-1} \mathrm{~m}^{-2}$ and $\mathrm{T}_{\text {sat }}=19^{\circ} \mathrm{C}$

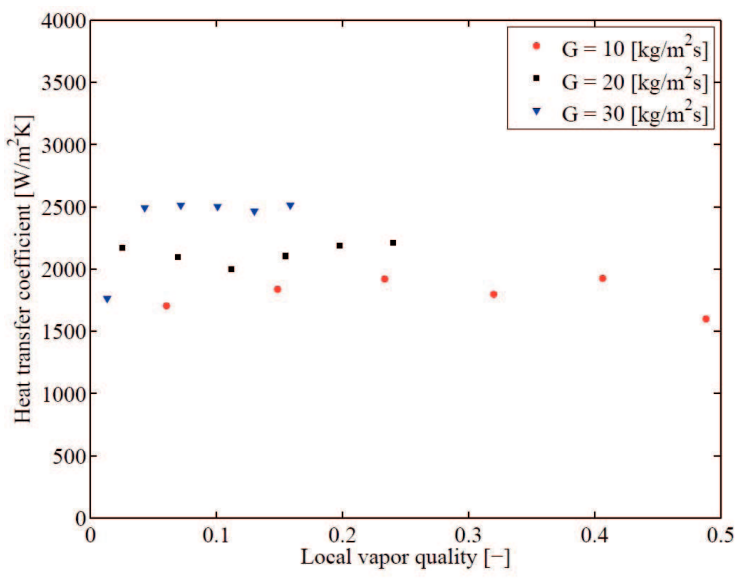

(a)

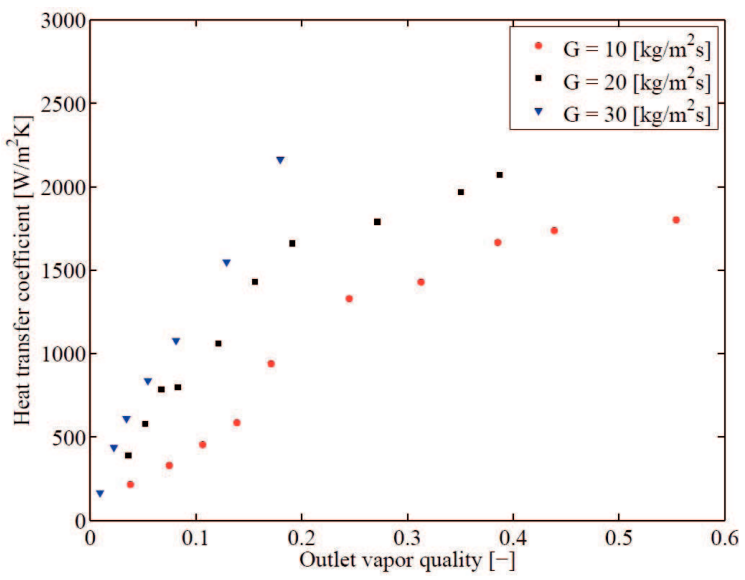

(b)

FIG. 11: Effect of mass flux on (a) quasi-local flow boiling heat transfer coefficients obtained at $\mathrm{T}_{\text {sat }}=25^{\circ} \mathrm{C}$ and $\mathrm{q}=$ $3500 \mathrm{Wm}^{-2}$ and (b) mean heat transfer coefficients at $\mathrm{T}_{\text {sat }}=25^{\circ} \mathrm{C}$

thus do not capture the trend in heat transfer with vapor quality). Therefore, they were in a better agreement with the mean database than the local heat transfer coefficients. Notably, Hsieh and Lin (2003) developed their method based on the heat transfer data for which the variation of vapor qualities from the PHE inlet to outlet was always relatively small $(\Delta x<0.2)$ and thus they came closer to getting quasi-local values than mean heat transfer data. Accordingly, Hsieh and Lin's (2003) method yielded reasonably good results, predicting $64.8 \%$ of the mean but only $45.5 \%$ of the quasi-local flow boiling database within a range of $\pm 30 \%$ with around $35 \%$ and $38 \%$ MAE, respectively. The Danilova et al. (1981) method was modified here based on the quasi-local database to capture the current test results for this small corrugation plate. Their expression now becomes

$$
\mathrm{Nu}_{t p}=13.02 \mathrm{Re}_{v}^{0.35} \mathrm{Bd}^{0.38} \mathrm{Bo}^{0.28} \operatorname{Re}_{l o}^{0.15}
$$

This updated method now captures $58.4 \%$ of the present quasi-local database with $\pm 30 \%$ and has a $35.5 \%$ MAE. 
TABLE 2: Summary of comparison between experimental data and prediction methods

\begin{tabular}{|c|c|c|c|c|c|c|}
\hline \multirow{2}{*}{ Correlation } & \multicolumn{3}{|c|}{ Mean data } & \multicolumn{3}{c|}{ Quasi-local data } \\
\cline { 2 - 7 } & $\mathrm{ME}^{a}$ & $\mathrm{MAE}^{b}$ & $\pm 30 \%^{c}$ & $\mathrm{ME}$ & $\mathrm{MAE}$ & $\pm 30 \%$ \\
\hline Donowski and Kandlikar (2000) & 95.1 & 110.3 & 37 & 23.2 & 63.1 & 32.2 \\
\hline Danilova et al. (1981) & 49.4 & 65.1 & 50.6 & -7.6 & 52.8 & 30 \\
\hline Han et al. (2003) & -7.1 & 39.8 & 42 & -39.2 & 55.8 & 16.1 \\
\hline Hsieh and Lin (2002) & 23.6 & 44.3 & 50 & -15.4 & 50.6 & 30.7 \\
\hline Hsieh and Lin (2003) & 24.8 & 34.7 & 64.8 & -16.7 & 38.3 & 45.5 \\
\hline Jokar et al. (2006) & 81.6 & 106.9 & 38.9 & 24.9 & 93.6 & 17.6 \\
\hline Tboas et al. (2012) & 30.9 & 64.2 & 26.5 & -9.2 & 74.4 & 15.7 \\
\hline
\end{tabular}

${ }^{a}$ Percentage of mean error, $(100 / n) \sum_{1}^{n}\left(h_{\exp }-h_{\text {pred }}\right) / h_{\exp }$, where $n$ is number of data.

${ }^{b}$ Percentage of mean absolute error, $(100 / n) \sum_{1}^{n}\left|h_{\exp }-h_{\text {pred }}\right| / h_{\text {exp }}$, where $n$ is number of data.

${ }^{c}$ Percentage of experimental data captured within $\pm 30 \%$.

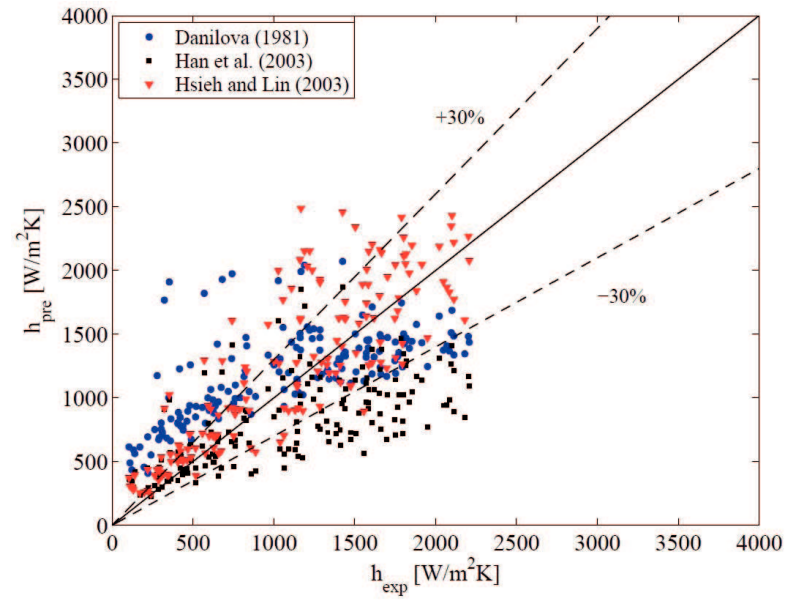

(a)

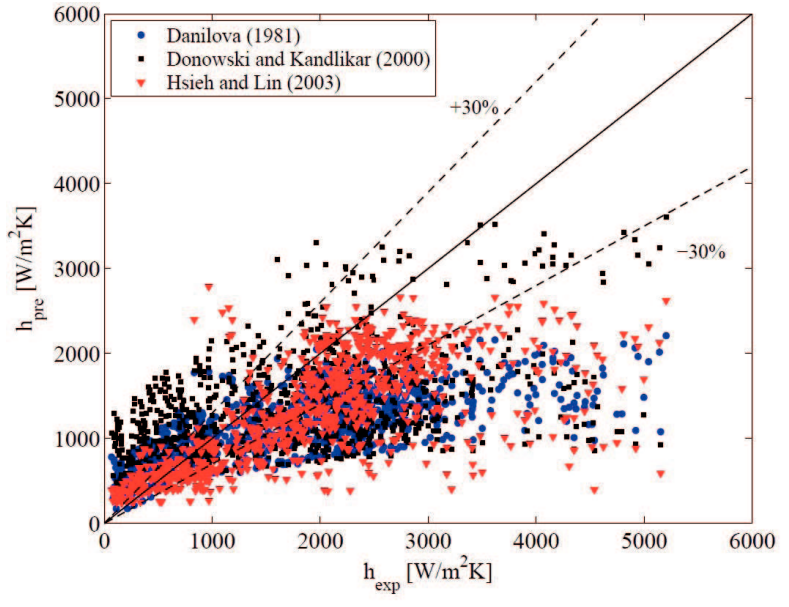

(b)

FIG. 12: Experimental flow boiling heat transfer data compared to the prediction methods; (a) mean heat transfer coefficients; (b) quasi-local heat transfer coefficients

\section{CONCLUSIONS}

A promising new compact plate heat exchanger (PHE) with thinner plates, a corrugation depth of $1 \mathrm{~mm}$, and a chevron angle $65^{\circ}$ was fabricated and tested here. A series of single-phase and two-phase flow boiling experimental tests was conducted to investigate single- and two-phase flow boiling heat transfer characteristics within the compact plate heat exchanger prototype. The major results can be summarized as follows:

- Experiments were carried out to address mean and local flow boiling heat transfer characteristics within the PHE. The influences of vapor quality, system pressure, heat flux, and mass flux on flow boiling heat transfer coefficients data were considered in detail. Based on the present experimental data, it is realized that all trends were similar to those typically observed for flow boiling inside tubes. 
- A new experimental approach (not before applied to PHEs) was introduced in this study to investigate highresolution local (pixel-by-pixel) evaporation heat transfer and pressure drops of R245fa within a compact prototype PHE, using an in-house calibrated IR camera.

- Several of the most-widely used prediction methods for saturated flow boiling of refrigerants in PHEs were evaluated with respect to the current mean and quasi-local (obtained in six windows) experimental database. The prediction methods showed a better agreement with the mean data rather than the local flow boiling heat transfer database. They typically tended to overestimate the low values of local heat transfer data (mostly pertinent to the low vapor qualities) while the higher local heat transfer coefficients were underestimated. This can be linked to the fact that they were originally developed according to the mean databases themselves and not local heat transfer data (such mean data tend to give the local heat transfer coefficient at the midpoint vapor quality of such tests and thus do not capture the trend in heat transfer with vapor quality).

- The quasi-local data were best predicted by the Hsieh and Lin (2003) method and a newly modified version of the Danilova et al. (1981) method.

- Additional experiments testing different fluids over a wider test range are required in order to extend the current database and make a comprehensive local flow boiling heat transfer and pressure drop database for PHEs. These are essential to develop more accurate and generalized prediction methods.

\section{ACKNOWLEDGMENTS}

The authors wish to thank the US Office of Naval Research (in particular the program director, Mark Spector) for the financial support provided for the project N000141210398.

\section{REFERENCES}

Akers, W. W., Deans, H. A., and Crosser, O. K., Condensation heat transfer within horizontal tubes, Chem. Eng. Process Symp. Ser., vol. 55, no. 29, pp. 171-176, 1959.

Cooper, M. G., Heat flow rates in saturated nucleate pool boiling-a wide-ranging examination using reduced properties. Adv. Heat Transfer, vol. 16, pp. 157-239, 1984.

Danilova, G. N., Azarskov, V. M. and Zemskov, B. B., Teploobmen V Plastinchatihispariteljan Razichnole Geometri (Heat transfer in plate evaporators of different geometry), Kholod. Tek., vol. 4, pp. 25-31, 1981.

Djordjevic, E. and Kabelac, S., Flow boiling of R134a and ammonia in a plate heat exchanger, Int. J. Heat Mass Trans., vol. 51, no. 25-26, pp. 6235-6242, 2008.

Donowski, V. D. and Kandlikar, S. G., Correlating evaporation heat transfer coefficient of refrigerant R-134a in a plate heat exchanger, in Engineering Foundation Conf. on Pool and Flow Boiling, Alaska, Paper 154, 2000.

Han, D. H., Lee, K. J., and Kim, Y. H., Experiments on the characteristics of evaporation of R410a in brazed plate heat exchangers with different geometric configurations, Appl. Thermal Eng., vol. 23, no. 10, pp. 1209-1225, 2003.

Hsieh, Y. Y. and Lin, T. F., Saturated flow boiling heat transfer and pressure drop of refrigerant R-410a in a vertical plate heat exchanger, Int. J. Heat Mass Transfer, vol. 45, no. 5, pp. 1033-1044, 2002.

Hsieh, Y. Y. and Lin, T. F., Evaporation heat transfer and pressure drop of refrigerant R410a flow in a vertical plate heat exchanger, J. Heat Transfer, vol. 125, no. 5, pp. 852-857, 2003.

Jokar, A., Hosni, M. H., and Eckels, S. J., Dimensional analysis on the evaporation and condensation of refrigerant R-134a in minichannel plate heat exchangers, Appl. Thermal Eng., vol. 26, no. 17-18, pp. 2287-2300, 2006.

Kandlikar, S. G., A model for correlating flow boiling heat transfer in augmented tubes and compact evaporators, ASME J. Heat Transfer, vol. 113, no. 4, pp. 966-972, 1991.

Khan, M. S., Khan, T. S., Chyu, M. C., and Ayub, Z. H., Evaporation heat transfer and pressure drop of ammonia in a mixed configuration chevron plate heat exchanger, Int. J. Refrig., vol. 41, pp. 92-102, 2014.

Kovalenko, L. M. and Maslov, A. M., Soviet plate heat exchangers, Konservnaya I Ovoshchesushil Naya Promyshlennost (in Russian), no. 7, pp. 15-17, 1970. 
Kumar, H., The Plate Heat Exchanger: Construction and Design, in Institute of Chemical Engineering Symp. Series, 1984.

Martin, H., A theoretical approach to predict the performance of chevron-type plate heat exchangers, Chem. Eng. Process.: Process Intensification, vol. 35, no. 4, pp. 301-310, 1996.

Muley, A., Manglik, R. M., and Metwally, H. M., Enhanced heat transfer characteristics of viscous liquid flows in a chevron plate heat exchanger, J. Heat Transfer, vol. 121, no. 4, pp. 1011-1017, 1999.

Rene, F., Leuliet, J. C., and Lanlande, M., Heat transfer to Newtonian and non-Newtonian food fluids in plate heat exchangers: Experimental and numerical approaches, in Food and Bioproducts Processing: Transaction of the IChE, Part C, vol. 69, no. 3, pp. 115-126, 1991.

Táboas, F., Vallès, M., Bourouis, M., and Coronas, A., Flow boiling heat transfer of ammonia/water mixture in a plate heat exchanger, Int. J. Refrig., vol. 33, no. 4, pp. 695-705, 2010.

Táboas, F., Vallès, M., Bourouis, M., and Coronas, A., Assessment of boiling heat transfer and pressure drop correlations of ammonia/water mixture in a plate heat exchanger, Int. J. Refrig., vol. 35, no. 3, pp. 633-644, 2012.

Vakili-Farahani, F., Agostini, B., and Thome, J. R., Experimental study on flow boiling heat transfer of multiport tubes with R245fa and R1234ze(E), Int. J. Refrig., vol. 36, no. 2, pp. 335-352, 2013.

Yan, Y. Y. and Lin, T. F., Evaporation heat transfer and pressure drop of refrigerant R134a in a plate heat exchanger, ASME J. Heat Transfer, vol. 121, no. 1, pp. 118-127, 1999. 